\title{
Fiscal austerity and the trade-off between public investment and social spending
}

\author{
Christian Breunig and Marius R. Busemeyer
}

\begin{abstract}
This article makes two claims: first, it argues that the impact of fiscal austerity varies across different types of public spending. In particular, we show that discretionary spending (public investment) is hit harder by fiscal austerity than enti tlement spending (public spending on pensions and unemployment) because of different institutional and political constraints. Second, we find that electoral insti tutions affect how governments solve this trade off. Discretionary spending is cut back more severely in countries with an electoral system based on proportional representation than in a majoritarian system. Our empirical analysis relies on a meth odological approach (composite data analysis) that takes into account interdepen dencies between budgetary categories. Using data for 21 Organisation for Economic Co operation and Development countries from 1979 to 2003, we find strong evidence for the varying impact of fiscal stress on the budget shares of discre tionary and entitlement spending as well as strong interactive effect between fiscal austerity and electoral institutions.
\end{abstract}

KEY WORDS Budgeting; comparative political economy; electoral system; fiscal austerity; public investments; welfare state policies.

The global and economic and fiscal crisis is increasingly translating itself into a crisis of public budgets. Scholars in comparative welfare state research have long been studying the politics of reform in 'hard times' (Stephens et al. 1999; see also Pierson 1994, 2001). The focus of this literature is to explain why and how governments might be able to fend off unpopular retrenchment reforms for at least some time (Weaver 1986), how eventually retrenchment pressure cuts into the 'soft underbelly' of social services, while preserving entitlement spending (Clayton and Pontusson 1998) and how if all else fails governments try to consolidate their budgets via cutting spending, increasing revenue, or levels of public debt.

This paper adopts a different approach. We start by assuming that at some point, governments can no longer resort to easy ways to avoid politically costly budget decisions and are then confronted with difficult political tradeoffs when deciding on the distribution of scarce public funds across different kinds of spending. Our contribution is to provide a theoretical argument on 
how governments address these political and budgetary trade-offs in times of fiscal crisis and how these trade-offs are influenced by the specific patterns of political accountability associated with different electoral systems.

In developing our argument and empirical model, we are less concerned with absolute reductions or expansions in the levels of public spending, but with changes in the composition of budgets, i.e., relative changes within a budget. We contend that entitlement programs are more protected from cutbacks in times of crisis than discretionary spending, because reformers of entitlement programs are confronted with strong institutional and legal constraints as well as the political opposition of large parts of the electorate. The main contribution of the paper, however, is to go one step further by showing how electoral institutions affect political trade-offs. Recent scholarship in this field (Chang 2008; Milesi-Ferretti et al. 2002; Persson and Tabellini 2004; Persson et al. 2007) argues that electoral institutions have strong effects on fiscal policy. This literature, however, has not looked at the interaction between electoral systems and fiscal crises and has neglected how fiscal policy is executed by specific budgetary decisions.

Our central argument is that patterns of public spending typically associated with specific electoral institutions are magnified during times of fiscal stress. In majoritarian systems, governments concerned with minimizing the electoral costs of crisis management have a strong incentive to shield discretionary types of spending from cutbacks, because their constituencies tend to be more concentrated in particular localities and/or policy areas. In electoral systems based on proportional representation (PR), policy-makers have different incentives because their re-election depends on the maximization of the vote share of their party and not on winning particular electoral districts. Governments in PR systems are more likely to protect entitlement programs from retrenchment because alienating the broad constituencies of these programs would significantly hurt their chances for re-election. Empirically, we verify our hypotheses with an analysis of public spending on pensions, unemployment and public investments in Organisation for Economic Co-operation and Development (OECD) countries, using an appropriate methodological tool - compositional data analysis - that takes into account the interdependency of budget shares.

The paper adds to the existing literature in three ways. First, scholarship in the tradition of the 'new politics of the welfare state' school of thought (Pierson 1994,2001 ) has mostly been concerned with explaining the resilience of contemporary welfare states. At the same time, and even before the current crisis, the political pressure to consolidate public budgets in OECD countries has been mounting continuously. Recent research has shown that welfare states in large part have been resilient to large-scale retrenchment (though see, e.g., Allan and Scruggs 2004 for a more nuanced perspective). However, the pressure might have been deflected to other parts of public budgets. For example, Clayton and Pontusson (1998: 95) show that while the reforms of the 1980s and 1990s did not lead to a significant reduction in overall level of social 
spending, governments have cut back the more vulnerable 'service components' of the welfare state. This finding is supported by Castles (2007) who notes a high degree of resilience in social spending associated with significant reductions in non-social spending. Our paper adds to this literature by showing that the onset of fiscal crisis aggravates budgetary trade-offs by maintaining or improving the relative budget share of entitlement spending, while reducing the share of discretionary spending such as public investments. Our perspective is thus much more encompassing than the one typically applied in welfare state research, because we look at the consequence of welfare state resilience on other policy areas that are not commonly regarded as being part of the welfare state (i.e., public investment).

Second, although studying the structure or composition of budgets has become an increasingly important research topic in the last couple of years (Chang 2008; Tsebelis and Chang 2004), most comparative analyses of the determinants of public spending still tend to look at different types of spending separately without taking account interdependencies between budget categories. This stands in contrast with the empirical reality of governmental decision-making, where policy-makers are constantly faced with decisions on how to allocate scarce public resources across budget categories. Relying on recent advances in statistical methods, we explicitly take into account the interdependency of budget categories. We model the impact of fiscal austerity on relative changes between spending categories given short-term budget constraints. This stands in contrast with the more commonly applied perspective which studies government reactions to austerity by focusing on changes in public indebtedness or tax revenues.

Finally, the paper adds to the growing literature studying the effects of electoral institutions on fiscal policy (e.g., Chang 2008; Iversen and Soskice 2006; Persson and Tabellini 2004). This literature has shown that electoral systems are associated with different patterns of public spending: PR systems favor large-scale spending programs with broad constituencies and majoritarian systems exhibit a bias in favor of targeted types of spending. However, to our knowledge, the issue of how fiscal crises affect these spending patterns has not yet been studied. Our paper thus moves beyond the pertinent literature in this field by showing that pressures of fiscal austerity significantly enhance the observed patterns.

The paper proceeds as follows: the next section develops our theoretical argument, followed by a brief section on operationalization and hypotheses. Subsequently, we introduce our estimation technique called compositional data analysis. We then engage in an empirical analysis of spending patterns in advanced OECD democracies from 1979 until 2003 and present the findings graphically. The final section concludes and discusses ideas for future research.

\section{FISCAL AUSTERITY, ELECTORAL INSTITUTIONS AND BUDGET TRADE-OFFS}

In times of fiscal crisis, governmental policy-makers face tough decisions and need to resolve difficult political trade-offs. Ultimately, the goal of governments 
is to minimize the electoral costs associated with the state of crisis. Governments can rely on various political instruments and strategies to achieve this goal, e.g., blame avoidance (Weaver 1986), obfuscation of real economic costs, or manipulating discursive frames (Vis and van Kersbergen 2007). Also, instead of pushing through with unpopular cuts in public spending, governments can simply increase revenues in order to balance the budget. The usual approach in the literature on the impact of fiscal austerity on the welfare state therefore is to focus on government reactions in terms of spending cuts in the 'soft' parts of the welfare state (Clayton and Pontusson 1998) or differences in strategies of budget consolidation (i.e., whether more focused on raising revenue, increasing debt levels, or cutting spending).

In contrast, we start out by assuming that unpopular retrenchment reforms can only be staved off for limited periods of time. Caught between a rock and a hard place and confronted with a multiplicity of organized interests and electoral demands, governments need to resolve difficult political trade-offs. We are interested in how governments solve these trade-offs on the expenditure side. Given a particular size of the budget, how do governments re-allocate scarce public resources across budget categories? And are government reactions related to political institutions, in particular the electoral system?

We develop our argument in two steps: first, we show how differences in the policy structure and associated institutional and political constraints increase the likelihood that discretionary public spending is cut back more than spending on entitlement programs in times of fiscal austerity. Second, and this is the main contribution of the paper, we postulate that electoral institutions are associated with differences in how adjustment pressures resulting from fiscal austerity are distributed across spending types.

Coming back to the first point: public policies and spending programs are associated with specific institutional and legal constraints which have an impact on their vulnerability for retrenchment reforms. A fundamental distinction exists between spending on entitlement programs and discretionary spending. In most cases, policy-makers cannot simply decide to reduce spending on established entitlement programs from one fiscal year to the next. Instead, they have to engage in the long and arduous process of changing the respective entitlement laws. Even then, governments can only change the parameters of entitlement programs such as eligibility criteria or benefit calculation formulas.

In contrast to entitlement spending, discretionary spending faces lower institutional constraints. There is no clearly defined right or entitlement to a certain amount of discretionary spending. The basis for the allocation of public funds is not an entitlement law; they depend on annual discretionary budget decisions by government. As a consequence, there is significant leeway with regard to the quantity and quality of the public good to be provided as well as when it should be provided. Policy-makers can easily decide to postpone or downgrade a particular discretionary investment, whereas in the case of entitlement programs, they are bound by existing legal constraints. 
Above and beyond institutional constraints, political interests significantly affect the government's decision function on the distribution of budget cuts. The seminal insight of the 'new politics of the welfare state' school (Pierson $1994,2001)$ is that welfare states are very resilient to retrenchment, because beneficiaries of entitlement programs can successfully lobby against cutbacks. In his account, Pierson emphasizes the role of organized interests. Complementary research on individual social policy preferences (Boeri et al. 2001) has shown that entitlement programs in general receive a large degree of public support and, as a corollary, retrenchment is very unpopular. Policy-makers are very sensitive to changes in the public mood, in particular with regard to popular entitlement programs (Soroka and Wlezien 2005). Therefore, a robust association between public support for the welfare state and policy output in terms of spending prevails (Brooks and Manza 2007). The strong support for the welfare state on the level of individual preferences can thus also explain 'why welfare states persist' (Brooks and Manza 2007) and why cuts in entitlement programs carry huge electoral risks.

Although entitlement programs enjoy broad political support, political resistance against cutting back discretionary spending can also be quite effective. Whereas entitlement programs - due to their institutional and legal nature define broad groups of beneficiaries, the constituencies of discretionary spending programs tend to be more concentrated in one particular locality or policy subfield (e.g., military spending or agricultural subsidies). As postulated in collective action theory (Olson 1965), small groups with special interests have a strong advantage over diffuse interests with regard to organization and mobilization. Furthermore, special interest organizations can capture parts of the government's bureaucratic apparatus and establish strong political bases in parliamentary committees (Olson 1984: 42-7). Governments, or policy-makers more generally, are thus confronted with a difficult political trade-off: on the one hand, they could decide to concentrate cuts on entitlement programs, alienating large parts of the electorate. On the other hand, cuts in discretionary spending programs would lead to a confrontation with powerful special interest groups.

Proceeding to the second step in our argument, we argue that the specific outcome of budgetary trade-offs is contingent on electoral institutions, because these are associated with different patterns of political accountability (Przeworski et al. 1999). A well-established finding in the literature is that patterns of public spending vary in line with electoral institutions (Chang 2008; Iversen and Soskice 2006; Milesi-Ferretti Perotti and Rostagno 2002; Persson and Tabellini 2004; Persson et al. 2007). In majoritarian systems, policymakers tend to favor spending programs that can be targeted on a particular constituency, often simply defined in terms of geography. This is because the policy-makers' chances for re-election depend on winning the majority in a particular electoral district. In contrast, policy-makers in systems based on PR have a bias in favor of large-scale entitlement programs with broad constituencies, because their chances for re-election depend on the maximization of the vote share of their respective party. 
Based on this insight, our main hypothesis is that electoral systems influence the way political and budgetary trade-offs are solved in times of fiscal crisis. We expect that the pressure of austerity aggravates political trade-offs, i.e., be associated with an even starker differentiation of spending patterns. Policy-makers in PR systems try to shield entitlement programs from cutbacks, because the electoral backlash of large parts of the electorate leads to huge political costs and significantly decreases their chances for re-election. As a consequence, retrenchment pressure is deflected to discretionary spending. Cutting back popular entitlement programs carries large political costs in majoritarian systems too. However, individual policy-maker's re-election depends on the support of particular geographical and/or policy-field specific constituencies and therefore discretionary spending is protected from cutbacks to a larger extent than in PR systems. To summarize, we expect the following hypotheses to hold:

Hypothesis 1: Increasing fiscal pressure is associated with a shift in budget shares in favor of entitlement programs and to the detriment of discretionary spending.

Hypothesis 2: The budget share of spending on entitlement programs is larger in PR systems, while that of discretionary spending is large in majoritarian systems.

Hypothesis 3: The joint effect of increasing fiscal pressure and electoral institutions is to aggravate the trade-off between entitlement and discretionary spending.

\section{OPERATIONALIZATION}

Our definition of a budgetary trade-off centers around the notion that, in the face of mounting fiscal pressure, one type of spending is systematically disadvantaged against another. We argue that entitlement spending should be less affected by retrenchment than discretionary spending. In reality, budget categories as documented in official statistics rarely fall into these neat categories of entitlement and discretionary spending. The empirical challenge is to identify spending types that (1) could plausibly be taken as typical examples of entitlement and discretionary spending, (2) are available in internationally comparable statistics for a sufficiently long time period and (3) take up roughly similar budget shares. In our view, the best candidates are public spending on pensions as an example of an entitlement program and public investment as an example of discretionary spending. Public spending on unemployment serves as an intermediary spending type. Similar to pensions, it is an entitlement program. The difference is that in the case of unemployment spending, policy-makers have more leeway to adapt the entitlement criteria (such as benefit levels or 
mandatory contribution periods) in the short term. As we are studying these budget categories jointly, our dependent variable is a compositional measure of the relative budget shares of these three spending types.

A final comment before we move on: we concentrate on the three budget categories mentioned above, because we are able to develop specific theoretical insights that expect distinct effects across these three categories. Much less can be said about other, residual budget categories that are less clearly identifiable as entitlement or discretionary spending, although future theorizing may allow us to expand our analysis to other budget categories. In the empirical analysis below, we add an additional residual category that captures the share of all other budget items in alternative model specification. This does not affect our results in a significant manner, although it reduces the over-time variation in budget shares.

Two ways for operationalizing fiscal pressures are common: changes in government net interest payments [as percentage of gross domestic product (GDP)] and changes in total government receipts (as percentage of GDP). Both operationalizations are based on the idea that government policy-makers make decisions about the distribution of funds on the basis of the current state of the budget. Interest payments are a frequently-used and often-cited heuristic that policy-makers employ during the deliberation processes of the annual budget and allow policy-makers to evaluate various planned expenditures against the current budgetary pressures. Receipts work in a similar fashion. A shortfall in collected taxes and other payments to the government is often understood as an early warning sign of a fiscal imbalance and therefore directly enter policy-makers' calculations on how to spend public monies. Hence, net interest payments as well as government receipts enter budget decisions as a direct and natural measure of fiscal stress. We employ both measures and detail their results below.

Our second core independent variable is the electoral system. In order to increase sample size and simplify interpretation of the results, we employ a dichotomous variable, which is assigned the value of 0 for majoritarian electoral systems and a value of 1 for PR and mixed systems such as Germany. The use of a dummy variable is standard in the literature (e.g., Persson and Tabellini (2004)) and the correlation between this dichotomous variable and alternative measures of the proportionality of the electoral system is very high (Milesi-Ferretti et al. 2002: 632).

We expect explanatory contributions from a number of other variables. First, we test whether the partisan composition of the government makes a difference. Prima facie, the deduction of partisan preferences on public investment or the general allocation of spending across budget categories is not obvious. Freeman and Alt (1994) could not show any influence of partisan factors on public investment. For Boix (1998), on the other hand, public investments are an important element of a leftist supply-side strategy. However, it could be argued that in times of fiscal stress, Social Democrats might be tempted to protect cherished welfare state policies, even if this means cutbacks in 
investment or education. Hence, instead of formulating ad hoc hypotheses, we treat the impact of partisanship as an empirical matter and leave its detailed study for future research.

Finally, we include a number of economic and demographic variables that are expected to have an impact on the relative importance of public investment vis$\grave{a}$-vis social spending. A larger population share of elderly people is expected to lead to an increase in the budget share of pension spending. Changes in the level of economic well-being (captured by GDP per capita) are hypothesized to contribute to higher levels of social spending (Wagner's law) and lower levels of public investment because less developed societies tend to spend relatively more on public infrastructure and investment. Higher levels of unemployment contribute to 'economic stress' and should have a negative impact on the share of investments, while the effect on the other two budget categories is ambiguous. We also include the total level of public spending to take into account the general budget constraint.

\section{DATA}

This study comprises yearly expenditures for pensions, public investments and unemployment for 21 OECD countries (Australia, Austria, Belgium, Canada, Denmark, Finland, France, Germany, Greece, Ireland, Italy, Japan, Netherlands, New Zealand, Norway, Portugal, Spain, Sweden, Switzerland, UK and the USA) for the years between 1979 and 2003. The data are collected from various OECD sources. Public spending on pensions and unemployment are taken from the OECD Social Expenditure Database. Public investment is defined as 'gross fixed capital formation' by government as provided in the OECD National Accounts. ${ }^{2}$

We stress that spending trade-offs are constrained by the development of each of the three categories and delineate a strategy for modeling this trilemma between pensions, investment and unemployment spending. We are able to illustrate some stylized facts about the trade-offs here. Table 1 in the online appendix shows that the median shares across the three items are 59\% for Pensions, 29\% for Investment and 13\% for Labor Markets. Again, to be clear here, the shares we are referring to are based on the three components of our analysis and not the whole budget. Almost all countries in our sample moved toward spending a bigger share on pensions (between 37\% and 84\%) in 2000 than in 1980. These increases came from siphoning off both unemployment spending and especially public investment (which is close to just a $10 \%$ share in some countries by 2000; see also Keman 2010).

We describe our covariates briefly. Table 1 in the online appendix contains the summary statistics. The data generally are measured annually across countries. Interests are the net government interest payments as percentage of GDP and Receipts are total government receipts as percentage of GDP. Both are supplied by the OECD Economic Outlook database. Data on Electoral institutions (a dummy variable for proportional systems) are taken from the Database of Political Institutions (Beck et al. 2001). Disbursements are total public 
disbursement as percentage of GDP (OECD Economic Outlook). Age over 65 measures the percentage share of the total population that is over 65 years old (OECD Health). Income per Capita is as measured as the national income per capita in US dollars (current prices, Purchasing Power Parity from OECD Factbook). Unemployment is a measure of the unemployment rate (commonly used definition, OECD Economic Outlook). We measure the per cent share of cabinet seats of Social Democratic parties using data from Schmidt (2007).

Our data were about $96.3 \%$ complete and we found no patterns suggestions that data were missing for systematic reasons. King et al. (2001) show that dropping missing cases from the sample introduces biases and recommend imputation instead. We use multiple imputation that is appropriate with time-series cross-sectional data via Amelia II (Honaker et al. 2006) and aggregate the estimation results over 10 imputations. Our sample contains 525 observations.

\section{METHODOLOGY: BUDGET COMPOSITIONS AND THEIR ANALYSIS}

A methodology for estimating the trade-offs between pensions, investment and labor market spending needs to take into account that multiple categories of spending are not independent from each other. Traditionally, researchers relied on linear regression or multi-equation models for estimating whether and how fiscal pressure impacts pension, investment and labor market shares of public spending. We briefly illustrate some pitfalls of ignoring the compositional nature of the data by both alternatives here.

A linear regression for a single category, e.g., pensions, faces two dangers. First, a budget share is bounded by $[0,1]$ - a country cannot spend less than nothing or more than all of the budget on pensions. Linear regression ignores this constraint and thus often produces impossible fitted values. Second, a single linear regression conceals the apparent trade-offs of budgeting. Consider an estimation showing that $\hat{\alpha}_{1}>0$ for the regression Pension $=\alpha_{0}+\alpha_{1}$ Left Government $+\varepsilon$. We might conclude that left governments increase the pension share of the budget. But, a mathematically identical but substantively different interpretation of the results are that left governments reduce the share of all other budget items. This leaves the question as to which other budget categories were cut.

Employing a multi-equation model, i.e., estimating pensions, investment and labor market spending with three separate linear regressions does not remedy this problem. First, an equation-by-equation approach ignores that the individual components are likely to be negatively correlated (if pension shares go up, then at least one of the other two components must be reduced). Second, the multi-equation model still ignores that the budget shares are bounded and sum to the total budget. Both shortcomings suggest that ignoring the compositional nature of the data introduces statistical and substantive problems.

Budgets can be modeled as a composition ${ }^{3}$ (Aitchison 1986). When we define a budget category ${ }^{4} w_{k i t}$ as the expenditures in category $k \in\{$ Pensions, Investment, Labor Market $\}$ by country $i$ in year $t$, then the unit of 
analysis is a single observed budget composition, defined as a collection of $w_{k i t}$ that collectively fulfill the budget constraint:

$$
w_{1 i t}+\cdots+w_{k i t}+\cdots+w_{K i t}=1, \quad 0 \leq w_{k i t} \leq 1
$$

The logarithms of the ratios of $w_{k i t}$ are independent and unbounded (Aitchison 1986) and can be jointly modeled with standard multivariate methods. The additive logratios are computed by selecting a reference category $K$ (i.e., the last category), then constructing the $K-1$ ratios of the composition and finally logging them. Hence, $y_{k i t}=\ln \left(w_{k i t} / w_{K i t}\right)$.

Relying on typical pooling assumptions in comparative politics, we can aggregate the logratios across space and time and estimate the following $K-1$ equations: $y_{k i t}=\phi_{k} y_{k, i, t} 1+\mathbf{x}_{i t}{ }_{1} \boldsymbol{\beta}_{k}+\varepsilon_{k i t}$. For each $y_{k i t}$, we arrange an equation regressing $y_{k i t}$ on its lagged value as well as a vector of lagged variables $\mathbf{x}_{i t} 1$ including Social Democrats, Income per Capita, Age over 65, Disbursements, $P R$ and Interest in the base model. We then add an interaction between $P R$ and Interest to the basic model. We estimate the system of $K-1$ equations by seemingly unrelated regressions (SUR) (Zellner 1962).

We aid interpretation of the results by translating the estimates of the SUR back into budget shares while accounting for the time dynamics. A clear ${ }^{5}$ way to understand the implications of the model is to examine the response of the composition to a permanent change in each covariate for the fifth year. We present the $90 \%$ confidence intervals for these quantities based on stochastic simulation of the iterated response variable (King et al. 2000). We report the changes in the shares of the three budget categories in order to facilitate comparison. For the interaction between fiscal pressure and political institutions, we show the joint effect of the three covariates (i.e., Interest, $P R$ and their interaction). ${ }^{6}$

\section{RESULTS}

We first provide and discuss the estimation results of our basic and interaction models and then introduce a set of alternative specifications in order to corroborate the robustness of these specifications. Our online appendix displays the SUR results for the four examined compositional data models as well as additional robustness checks. We calculate the expected changes in the budget share after five years from a change in each covariate. In general, we evaluate the counterfactual of a one standard deviation change in the covariate. Dot plots display the point estimates and $90 \%$ confidence intervals for each budget category. Each row of the plots shows the effect of a change in the listed covariate on all three budget categories while holding other variables constant. Each column represents a different budget category. For models that include an interaction, we display the combined effect of the three estimated covariates (i.e., fiscal pressure, proportional system and their interactive term). Figure 1 shows the following results. 


\section{Influence of fiscal pressure}

Intensified fiscal austerity - captured by increases in net interest payments - has distinct effects on each of the three budget shares. In particular the top plot of Figure 1 suggests that an increase in Interest payments by 3\% of the GDP leads to an increase in the share of pension spending by more than $1 \%$, while investment spending loses nearly $2 \%$ of its share. These findings are statistically significant. The estimated size is substantial when we recall that, for several countries in 1980, pensions and public investments covered a circa 40\% share each among the three examined budget functions. As expected, increasing fiscal pressure does not lead to a statistically significant change in public spending on unemployment. The estimated effects across the three spending categories provide strong evidence for the divergent effect of fiscal pressure within budgets (Hypothesis 1). Fiscal pressure results in cutbacks of discretionary types of public spending such as public investments. In contrast, the share of the budget for spending on entitlement programs, such as pensions, can still increase since they are protected by institutional lock-in and strong clientele groups.

\section{Alternative measure of fiscal pressure}

In order to affirm the core finding that fiscal pressure generates a trade-off between social spending and public investment and that investment loses in this trade-off, we re-estimate our model with a common alternative measure of fiscal pressure. Economists, policy-makers and scholars consider a reduction in government receipts to be an important indictor for imminent fiscal consolidation pressures. Therefore, we re-estimate the model using total government receipts as a percentage of GDP. The third plot in Figure 1 shows that a reduction in Receipts by 9\% (i.e., about one standard deviation in the sample) is expected to increase the share of pensions spending by nearly $4 \%$ ceteris paribus. This hypothesized revenue shortfall also corresponds to a circa 5\% cut in the share of investment. These estimates are statistically significant. Decreasing government receipts marginally increase the share of unemployment spending; however the confidence bands clearly overlap with zero. This re-estimation bolsters our initial finding: fiscal pressure, operationalized either as increased interest payments or reduced government receipts, leads to a relative (i.e., proportions of a pie) shift in governmental resources away from discretionary spending, such as public investments, toward entitlements, such as pensions.

\section{Influence of electoral system}

We hypothesize that electoral systems influence the division among discretionary and entitlement spending. Due to differences in how politicians are held accountable by voters, the budget share of spending on entitlement programs is bigger in proportional systems, while that of discretionary spending is large 


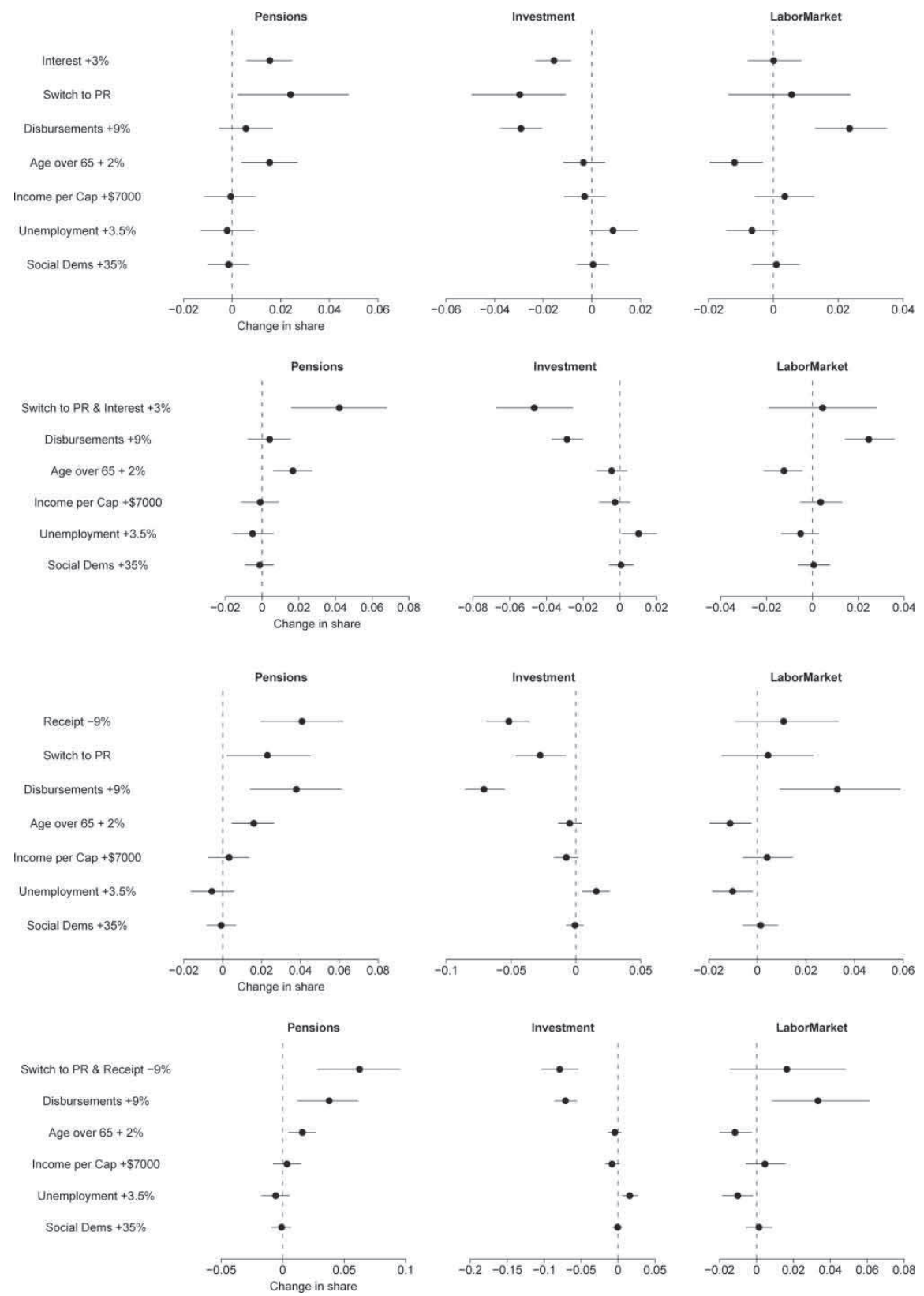

Figure 1 Estimated change in the share of the budget after five years. The top two plots displays the base and interactive models for interest and the bottom two present the results for receipts. Plots show the expected change in the share by budget category after five years under the counterfactual listed at the right. Each row lists a distinct counterfactual, while each column is a different budget category. Horizontal lines are the 90 per cent confidence bands 
in majoritarian systems. The first and third plots in Figure 1 display the estimated effects of a counterfactual switch from a majoritarian to a PR system. The top plot suggests that this switch, on average, would result in a roughly $2.5 \%$ increase in the budget share of pensions and a circa 3\% reduction in the shares of public investment. The third plot of Figure 1 indicates that the size and statistical significance of electoral systems are essentially replicated in models that use Receipts instead of Interest, lending further credence to the robustness of our findings. As expected, a difference in the set-up of the electoral system does not lead to a statistically significant shift in the share of labor market spending.

\section{Interaction between fiscal pressure and electoral system}

We expect that, in times of fiscal pressure, the trade-off between mandatory and discretionary spending is exacerbated by the influence of electoral systems. We test this interactive hypothesis by distinguishing between majoritarian and proportional electoral systems. The first row in the second and bottom plots of Figure 1 displays the counterfactual of increasing fiscal pressures and changing the electoral system. In other words, this row combines two individual and one interactive variables. In the second plot of Figure 1, we display the counterfactual of increasing Interest by 3\% and switching from a majoritarian to a PR electoral system. The estimated effects for the three budget functions follow the hypothesized direction and are statistically significant for pensions and public investment. Most importantly, when compared to the baseline model without the interaction effects, the size of the estimated effects increases. Substantively, this means that when fiscal pressure is combined with PR, the share of pensions increases by over $4 \%$ and the share of investment is reduced by more than $5 \%$. The presence of a proportional system more than doubles the estimated effects of fiscal pressure.

When we replace interest payments with Receipt as an indicator of fiscal pressure (top row in bottom plot of Figure 1), the size of the estimated effects is even larger. A reduction in government receipts by $9 \%$ of GDP, combined with a change to PR, is estimated to result in a nearly $10 \%$ shift away from public investment and an increase of nearly $6 \%$ in the share of pension spending. This finding nicely depicts how majoritarian and proportional electoral systems under fiscal pressure resolve the trade-off between entitlement and discretionary spending in starkly different terms.

\section{Other covariates}

First, increases in the size of the pie, i.e., increases in total size of the budget (disbursements), are not evenly distributed across the three components. Increases in total disbursements have a positive and, for three out of four models, a statistically significant influence on the share of pension spending. A one standard deviation increase in Disbursements results in a change in the share of pensions of 
at least $2 \%$. Across the four models, we do not find much evidence that an increase in the size of the budget leads to a change in the share of labor market spending. However, changes in the size of the budget influence the shares of public investments. Roughly speaking, a standard deviation increase in Disbursements results in an at least 3\% decrease in the share of investment (see second row in the top plot of Figure 1). For the interaction models in Figure 1, the estimated effect is nearly three times as large. Substantively, the finding suggests that the growth of government since the mid-1970s did not lead to a proportionate increase in public investment spending.

Second, the four models also indicate that an increase $(+2$ per cent points, i.e., one standard deviation) in the size of the elderly segment of society leads to an at least $1.5 \%$ increase in the share of pension spending. This finding is neither new nor surprising. It goes back to Wilensky's (1975) claim about the logic of industrialism and reveals that demographic changes are a powerful determinant of public spending. Yet, the compositional analysis also reveals that the increase in pensions is compensated by a cut in the shares of labor market and public investment spending. While the confidence band for public investment slightly overlaps with zero, the estimated changes in the shares of labor market spending are statistically significant and negative. In short, the estimations imply that demographic trends do not just affect one spending function but also the trade-offs among them - an aging population is expected to lead to resource shifts toward pensions at the expense of labor market spending.

Third, we find no statistically significant effect of Income per capita on the three spending categories. A standard deviation increase in income $(\$ 7000$ per capita) results in a decrease in the share of public investment and an increase in the share of unemployment spending by about the same size. These effects as well as the influence of income per capita on the share of pension spending are not statistically significant across the four models. These findings might provide at best a speculative hint with regard to public preferences on the welfare state. An increase in the overall well-being of citizens results in a shift from public investment to 'luxury goods', such as social protection in terms of pensions and unemployment.

Fourth, as the top plot in Figure 1 and the other models indicate, an increase of Unemployment by $3.5 \%$ does not have a statistically significant effect on the share of pension spending. A rise in unemployment, however, does show the trade-off between spending on labor market policies and public investment. While public investment's share rises by about 1\% (across models), the budget share of spending on unemployment is reduced by roughly the same amount. These results are statistically significant in the models with Receipts as a measure of fiscal pressure (Figure 1). This finding is curious and counterintuitive, because it suggests that public investment can be used as a labor market tool to boost the economy. It seems that particularly in countries without an encompassing welfare state such as Japan or Canada, public investments could be increased to expand public employment opportunities. Clearly, more research is needed here. 
Finally, we do not find any systematic effect of the cabinet share of Social Democratic parties on any of the three spending categories in our model specifications. ${ }^{7}$ Leftist cabinets do not alter the share of pensions, investment and labor market spending in substantively meaningful ways. Two speculative arguments can be proposed to account for this null finding. First, government parties might differ more with regard to the overall level of public spending than with the actual distribution of spending across different budget categories. So far, we lack an encompassing theory of partisan differences on budget categories, but it is reasonable to assume that, within given budgetary constraints, government parties will differ in their priorities. For example, leftist parties will favor spending on social policies and education, whereas rightist parties prefer spending on defense and homeland security. Thus, the second plausible explanation of the null finding is that parties in government are constrained by institutions and politics to privilege entitlement spending over discretionary spending, although they might have different budgetary priorities.

We conducted several robustness checks, which, due to a lack of space, could not be included in the main text of the article. The interested reader is referred to the online appendix. In brief, we show that operationalizing fiscal pressure as gross debt, adding the share of the remaining budget items and excluding European countries in the estimation does not affect the basic findings in any significant way.

\section{DISCUSSION AND CONCLUSIONS}

The resilience of the welfare state is intimately linked to the malleability of discretionary spending, especially public investment. Comparative welfare state research in the tradition of Pierson's 'new politics' approach is primarily concerned with explaining the resilience of welfare states. However, this perspective captures only one half of the underlying dynamic of retrenchment, because it neglects the effects of welfare state resilience on other policy fields. Pierson cites the 'imposition of concrete losses on a concentrated group of voters in return for diffuse and uncertain gains' in the future (Pierson 1994: 8) as an important factor preventing far-reaching retrenchment. We argue that in the case of discretionary spending, the distribution of costs and benefits across time is the other way around: when policy-makers postpone or cut back public investments, they immediately gain by saving discretionary spending, and the associated political costs will be lower than in the case of entitlement spending.

We also find that the trade-off between entitlements and discretionary spending is sharpened by differences in the underlying electoral institutions. Because majoritarian and proportional electoral systems generate distinct linkages between constituencies and legislators in terms of accountability and representation, policy-makers cater to different interests. In majoritarian systems, policymakers protect discretionary spending, which can be geographically targeted and employed in important swing districts, at the expense of entitlement 
spending such as pensions. In contrast, politicians under PR appeal to broad, national constituencies often tied to societal cleavages such as class by shifting resources from discretionary to social spending in times of fiscal pressure.

Our empirical analysis has a sobering policy implication: redirecting public funds away from entitlements toward discretionary spending and public investment is an unlikely and rare feat. It may be that policy-makers are well aware of the fact that the identified budgetary trade-offs do exist and might become problematic for long-term economic development. In addition to confirming this widely held belief, this article shows that the specific design of electoral institutions matters as well. In countries with PR electoral systems, increasing public investments is harder than in majoritarian countries because of the different electoral incentives that policy-makers face. The fact that most member states of the European Union have PR electoral systems has so far not been recognized as a possible explanation for the difficulties that these countries have with re-directing resources from entitlement to discretionary spending.

Biographical notes: Christian Breunig is Assistant Professor at the Department of Political Science, University of Toronto, Canada. Marius Busemeyer is Professor of Political Science at the University of Konstanz, Germany.

Address for correspondence: Christian Breunig, Department of Political Science, University of Toronto, Sidney Smith Hall, Room 3018, 100 St. George Street, Toronto, Ontario M5S 3G3, Canada. email: c.breunig@utoronto.ca/ Marius R. Busemeyer, Lehrstuhl für Politikwissenschaft, Fachbereich Politikund Verwaltungswissenschaft, Universität Konstanz, Fach D 79, D-78457 Konstanz, Germany. email: Marius.Busemeyer@uni-konstanz.de

\section{ACKNOWLEDGEMENTS}

We would like to thank John Ahlquist, Achim Goerres, Torben Iversen, David Rueda, Steffi Walter, Erik Wibbels, the anonymous reviewers of the journal and Jeremy Richardson. Previous versions of the paper have been presented at the MPSA, ECPR and DVPW meetings as well as the comparative politics workshop at Oxford University. We thank the participants of these events for valuable comments.

\section{NOTES}

1 Readers who remain skeptical about the compostional approach and prefer a speci fication in levels of spending are referred to the online appendix (available at www. polver.uni konstanz.de/busemeyer/). There, we provide regressions with levels as dependent variables and some detail discussion on the drawbacks of this approach.

2 This definition of public investment is the commonly used one (cf. Keman 2010). It includes government spending on the construction of infrastructure (streets, rail ways,...), on the purchase of capital goods by government (health care equipment in hospitals, office machinery,...), as well as expenses to ameliorate and maintain 
the existing capital stock. It does not include types of spending that some might want to regard as investment as well (i.e., spending on teachers in education).

3 Other political science applications include Adolph (2006) and Katz and King (1999). We follow Adolph et al. (2008) here.

4 Theoretically, it is of course possible to add several other budget categories or a residual budget group [i.e. Total (Pension + Labor Market + Investment)] Neither option is particularly satisfying. The first option demands that researchers identify and hypothesize across the proper division of a budget. The second option simply shows that the residual budget category is not correlated with the proposed covariates.

5 It is impractical to consider the whole impulse response function with that many components and covariates.

6 All statistical work was conducted in R Development Core Team (2008). We thank Chris Adolph for the rope ladder plots in his tile package.

7 Even when we replace the simple percentage of Social Democrats in government with Cusack's measure of the cabinet center of gravity, the results are virtually unaffected.

\section{REFERENCES}

Adolph, C. (2006) 'The dilemma of discretion: career ambitions and the politics of central banking', unpublished manuscript, Center for Statistics and the Social Sciences, University of Washington.

Adolph, C., Breunig, C. and Koski, C. (2008). 'Something's got to give: the political economy of state budget trade offs', American Political Science Association Annual Meeting, Boston, MA, 29 August.

Aitchison, J. (1986) The Statistical Analysis of Compositional Data, London: Chapman and Hall.

Allan, J.P. and Scruggs, L. (2004) 'Political partisanship and welfare state reform in advanced industrial societies', American Journal of Political Science 48(3): 496512

Beck, T., Clarke, G., Groff, A., Keefer, P. and Walsh, P. (2001) 'New tools in compara tive political economy: the database of political institutions', World Bank Economic Review 15(1): 16576.

Boeri, T. et al. (2001) 'Would you like to shrink the welfare state? A survey of European citizens', Economic Policy 16(32): 950.

Boix, C. (1998) Political Parties, Growth, and Equality: Conservative and Social Democratic Economic Strategies in the World Economy, Cambridge: Cambridge University Press.

Brooks, C. and Manza, J. (2007) Why Welfare States Persist: The Importance of Public Opinion in Democracies, Chicago: University of Chicago Press.

Castles, F.G. (2007) 'Testing the retrenchment hypothesis: an aggregate overview', in F.G. Castles (ed.), The Disappearing State? Retrenchment Realities in an Age of Globalisation, Cheltenham: Edward Elgar, pp. 1943.

Chang, E.C.C. (2008) 'Electoral incentives and budgetary spending: rethinking the role of political institutions', The Journal of Politics 70(04): 108697.

Clayton, R. and Pontusson, J. (1998) 'Welfare state retrenchment revisited: entitlement cuts, public sector restructuring, and inegalitarian trends in advanced capitalist societies', World Politics 51(1): 6798.

Freeman, J.R. and Alt, J.E. (1994) 'The politics of public and private investment in Britain', in T. Janoski and A.M. Hicks (eds), The Comparative Political Economy of the Welfare State, Cambridge: Cambridge University Press, pp. 13665.

Honaker, J., Blackwell, M. and King, G. (2006) Amelia II: a program for missing data, http://gking.harvard.edu/amelia/ 
Iversen, T. and Soskice, D. (2006) 'Electoral institutions and the politics of coalitions: why some democracies redistribute more than others', American Political Science Review 100(02): 16581.

Katz, J.N. and King, G. (1999) 'A statistical model for multiparty electoral data', American Political Science Review 93(1): 1532.

Keman, H. (2010) 'Cutting back public investment after 1980: collateral damage, policy legacies and political adjustment', Journal of Public Policy 30(2): 16382.

King, G., Honaker, J., Joseph, A. and Scheve, K. (2001) 'Analyzing incomplete political science data: an alternative algorithm for multiple imputation', American Political Science Review 95(1): 4969.

King, G., Tomz, M. and Wittenberg, J. (2000) 'Making the most of statistical analyses: interpretation and presentation', American Journal of Political Science 44(2): 34155.

Milesi Ferretti, G.M., Perotti, R. and Rostagno, M. (2002) 'Electoral systems and public spending', Quarterly Journal of Economics 117(2): 60957.

Olson, M. (1965) The Logic of Collective Action: Public Goods and the Theory of Groups, Cambridge, MA: Harvard University Press.

Olson, M. (1984) The Rise and Decline of Nations: Economic Growth, Stagflation, and Social Rigidities, New Haven, CT: Yale University Press.

Persson, T., Roland, G. and Tabellini, G. (2007) 'Electoral rules and government spending in parliamentary democracies', Quarterly Journal of Political Science 2(2): 15588.

Persson, T. and Tabellini, G. (2004) 'Constitutional rules and fiscal policy outcomes', The American Economic Review 94(1): 2545.

Pierson, P. (1994) Dismantling the Welfare State? Reagan, Thatcher and the Politics of Retrenchment, Cambridge: Cambridge University Press.

Pierson, P. (2001) The New Politics of the Welfare State, New York: Oxford University Press.

Przeworski, A., Stokes, S.C. and Manin, B. (1999) Democracy, Accountability, and Representation, Cambridge: Cambridge University Press.

R Development Core Team (2008) R: A Language and Environment for Statistical Computing, Vienna: R Foundation for Statistical Computing.

Schmidt, M.G. (2007) The partisan composition of OECD country governments, 1945 2005, dataset, unpublished dataset, Department of Political Science, Univer isty of Heidelberg, Germany.

Soroka, S.N. and Wlezien, C. (2005) 'Opinion policy dynamics: public preferences and public expenditure in the United Kingdom', British Journal of Political Science 35(4): 66589.

Stephens, J.D., Huber, E. and Ray, L. (1999) 'The welfare state in hard times', in H. Kitschelt, P. Lange, G. Marks and J.D. Stephens (eds), Continuity and Change in Contemporary Capitalism, New York: Cambridge University Press, pp. 16493.

Tsebelis, G. and Chang, E.C.C. (2004) 'Veto players and the structure of budgets in advanced industrialized countries', European Journal of Political Research 43(3): 44976.

Vis, B. and van Kersbergen, K. (2007) 'Why and how do political actors pursue risky reforms?', Journal of Theoretical Politics 19(2): 15372.

Weaver, R.K. (1986) 'The politics of blame avoidance', Journal of Public Policy 6(4): 37198.

Wilensky, H.L. (1975) The Welfare State and Equality: Structural and Ideological Roots of Public Expenditures, Berkeley: University of California Press.

Zellner, A. (1962) 'An efficient method of estimating seemingly unrelated regresions and tests for aggregation bias', Journal of the American Statistical Association 57(298): 34868. 